\title{
From One Medium to Another: Continuing the Narrative World on Twitter and Facebook
}

\author{
Parul Jain, Ohio University, USA \\ Amanda Weed, Ohio University, USA \\ Pamela Walck, Ohio University, USA
}

\begin{abstract}
Using narrative processing approach and uses and gratification theory, this study examined the motivations behind audience members desire to use social networking sites (SNS) Facebook and Twitter to: 1) connect with entertainment shows, 2) engage with characters on those shows, and 3) to engage with the actors that play those characters. After exposing participants to an episode of a show to gauge their engagement, they were asked to complete a questionnaire. The results suggest that levels of transportation predict likelihood of connecting with the show on social networking platforms. The levels of identification and parasocial interaction experienced during viewing predict the likelihood of following the character and the actor that played that role. Parasocial interaction with a character mediated the relationship between source attraction and connecting with the character and the actor on SNS. Theoretically, this research extends uses and gratification and narrative processing in the area of social networking research. Further theoretical and practical implications are discussed.
\end{abstract}

Keywords: social networking sites, narrative processing, transportation, identification, parasocial interaction, entertainment education 
Almost three quarters of the adults in the U.S. use some social networking site, with Facebook and Twitter being the dominant networks (PEW, 2013). Therefore, most organizations, including major broadcasters in the U.S., now employ some form of social networking platform to stay connected to their consumers. Television networks, for example, utilize social networking sites (SNS) for publicity, to provide information, and to enhance engagement among other things (Ciacu \& Tanase, 2012; Lin \& Pena, 2011).Spikes in Twitter activity correspond with show airtimesand drama-based programming seems to invoke more user engagement than other genres such as reality shows (Larsson, 2013; Lin \& Pena, 2011). For example, Anderson Cooper, host of the show Anderson $360^{\circ}$ engages audience via his blog on Tumblr and Pinterest while former news anchor and ABC talk show host Katie Couric used her significant presence on various social platforms to promote her program, Katie (Albiniak, 2012a, 2012b). While there is research that examines TV networks' use of Twitter as a tool for audience engagement and viewers' use of news-related information on various social media platforms, there is little information on motivations behind audience engagement with entertainment shows with a presence on social media (Greer \& Ferguson, 2011a, 2011b; Tully \& Ekdale, 2014).

Utilizing survey methodology and uses and gratification as a theoretical framework, this study examines the influence of narrative involvementonmessage recipients' subsequent engagement with the show and its characters on a social media platform after the viewing experience has ended. Specifically, we examine the factors that influence viewer motivations for post-viewing engagement with the show Mad Men and its main protagonist Don Draper and actor Jon Hamm (who plays the role of Don Draper) on two social network platforms, Facebook and Twitter. Given, the statistics demonstrating a positive relationship between program-related twitter activity and the show's television ratings (Nielsen, 2013), understanding the message factors carried over post-viewing may provide an insight into the reasons that drive audience to continue the connection with the show after it has ended. Theoretically, this research informs narrative transportation and entertainment education efforts by better understanding the factors that may influence message recipients after the termination of the message. 


\section{Uses and Gratifications and Narrative Involvement}

Uses and gratification perspective can be applied to this research to understand motivations behind connecting with someone via social media. The traditional view of uses and gratification research posits that audiences are active media users who are free to choose from various forms of mass media to gratify certain social and psychological needs (Katz, Blumler, \& Gurevitch, 1973; Rubin, 2009). With the advent of so many media choices, this perspective becomes more relevant as today's media user is free to select from a multitude of media options (Rubin, 2009; Ruggiero, 2000). Naturally, there has been a surge in studies trying to understand motivations behind video game use (Reijmersdal, Jansz, Peters, \& Noort, 2013), internet use (Papacharissi $\&$ Rubin, 2000) and use of SNS platforms (Pai \& Arnott, 2013) that are framed under the uses and gratification perspective. We argue and test in this research that various forms of narrative involvement, elaborated in the next section, creates a need for connection that extends past viewing that is gratified through extended involvement with television shows viavarious social media platforms.

\section{Narrative Involvement}

Transportation or absorption in a narrative is a cognitively engaging activity that blurs the boundaries between narrative and real world (Green \& Brock, 2000, 2002). Transportation is a "distinct mental process, an integrative melding of attention, imagery, and feelings, which may mediate the impact of narratives on beliefs" (Green \& Brock, 2000, p. 701; 2002, p. 324). Consequently, being transported means that people temporarily forget some aspects of reality and become immersed in the world of narrative (Green \& Brock, 2000, 2002). That is, the message recipient becomes "cognitively and affectively engaged in the narrative" (Slater, 2002, p. 179). Transportation in a narrative could persuade message recipients since they are less critical of the narrative content and therefore less likely to counter-argue the story consistentclaims (Green \& Brock, 2002; Moyer-Guse, 2008; Slater \& Rouner,2002); are more likely to perceive the events in the narrative to be real, which can influence attitudes due to mimicry of direct experience (Green \& Brock, 2002); and could develop affective feelings toward the characters which in turn may impact beliefs (Green \& Brock, 2000, 2002).

Although research has provided enough evidence to suggest that narrative could still influence the message recipient once the transportation experience has ended (Bilandzic \& Busselle, 2008; Green \& Clark, 2012), what we don't know is how participants fulfill the need to 
maintain connection to the narrative, if they so desire, after the viewing is terminated. While repetitive watching is one option, social media provides an avenue for social involvement where people can still feel connected to the show without leaving their reality by engaging in conversations with fellow aficionados of the program.

Previous research suggests that some of the reasons for engaging in social media by undertaking activities such as sharing information, "liking" something, or "following" someone has to do with intrinsic and/or image-related utilities (Toubia \& Stephen, 2013). Intrinsic utility refers to engaging in social media activity such as sharing content that may satisfy intrinsic motivation and amassing followers may satisfy image-related utility that encompasses user's identity and sense of self-worth. Contextualizing this information to the current research, a viewer may decide to follow a particular show because they are so cognitively engaged in the show that they may want to continue the hedonistic experience by interacting with like-minded individuals. Alternatively, the viewers of a particular show may want to communicate a message to their social circle that they are fans of the program by clicking like or following the show on SNS.Some of the other motivations behind activities such assharing news (e.g. about a particular character) on SNS platforms may be to stir conversation with fellow users and to maintain a level of personal connection (Greer \& Ferguson, 2011). Specifically, Wohn and Eun-Kyung (2011) found four prevailing message types when examining Tweets posted during television viewing, which include: 1) Attentionseeking (self-reference), 2) Information (program-reference), 3) Emotion (self-reference), and 4) Opinion (program-reference). Indeed, social media based brand communities are considered a way for individuals with similar interest to virtually congregate for various purposes such as self-expression and participation, which in turn, further intensifies the investment one experiences with a brand - in the present context, a television show or it's character/actor (Habibi, Laroche, \& Richard, 2014).

Based on this we propose that:

H1: Transportation into a program predicts using that program's social networking platforms

While transportation is concerned with the overall narrative, message recipients can also become involved with the characters in the narrative via identifying with the protagonist during the show and developing parasocial Interaction (PSI) with them after the show has ended. 
Identification involves taking on the identity of the character by merging one's self with the character during the viewing experience (Cohen, 2001). In conceptualizing identification with media characters, Cohen (2001) notes: "When identifying with a character, an audience member imagines him-or herself being that character and replaces his or her personal identity and role as audience member with the identity and role of the character within the text" ( $p$. 251). Identification has four dimensions - empathy, cognitive aspect, motivational aspect, absorption - and includes adopting both cognitive as well as the affective identity of the character and a complete immersion in the text (Cohen, 2001). While the dimension of absorption is common to identification and transportation, these are distinct concepts as identification goes beyond the involvement with the narrative-the primary focus of transportation - to the involvement with the characters in the narrative (Moyer-Guse, 2008).

While identification occurs during viewing and is perceived to end after the viewing session has concluded, parasocial interaction (PSI) — defined as considering the characters in the narrative as friends and developing a bond with them without ever meeting the characters in person-extends beyond the viewing experience (Cohen, 2006; Giles, 2002; Horton \&Wohl, 1956). PSI is defined as an "extension of normal social activity by considering shared and different qualities of social and parasocial encounters" (Giles, 2002 p. 298). Viewers who form parasocial interaction with media characters are generally aware that these characters are not real (Cohen, 2006; Giles, 2002; Horton \& Wohl, 1956; Moyer-Guse, 2008). To experience parasocial interaction, neither similarity, nor role-takingof the media character, is an absolute must although it might aid the "relationship" (Rubin \& McHugh, 1987; MoyerGuse, 2008). Because parasocial interaction extends beyond the viewing experience, message recipients could seek out the characters with whom they experience PSI, and the actor that played the role of that character, to gratify the need to connect. In other words, while identification is supposed to end with the viewing experience, PSI may continue even after the show has ended.Since SNS provide an avenue to the viewers to continue the "interaction" with the characters and actors that play those characters beyond the viewing situation and the recent calls to investigate how these processes unfold online (Cohen, 2014) we propose the following:

H2: PSI with the character would predict following the a) character and the b) actor on SNS 
RQ1: How does identification with the character influence following the a) character and the b) actor on SNS?

Liking-also referred to as social attraction to a character-refers to positive evaluationsleading to a generally favorable attitude toward them (Cohen, 2001; Giles, 2002; Moyer-Guse, 2008). Liking of media characters was a part of interpersonal attraction to physically thin media personalities and positively predicted eating disorders in one study (Harrison, 1997). Social attractionto the actress, Anne Hathaway, successfully predicted parasocial interaction with the character played by Hathaway, even when she was portrayed in a stigmatized role (Chung \& Moyer-Guse, 2012; Moyer-Guse, 2008). Perhaps the level of attractiveness that a viewer feels toward a character would influence the level of engagement. In otherwords, if following an actor and a character on SNS are ways to engage in parasocial interaction, then this should be influenced by how much the character is liked in the first place. Indeed past research has demonstrated a positive relationship between PSI and social attractiveness (Rubin \& McHug, 1987). Therefore, it stands to reason that viewers who experience stronger levels of attraction would be more likely to follow the actor and character, which would be mediated via PSI as indicated in Figure 1 and 2. More formally,

H3: PSI with the character would mediate the effect of social attraction on a) following the character on SNS and b) following the actor on SNS.

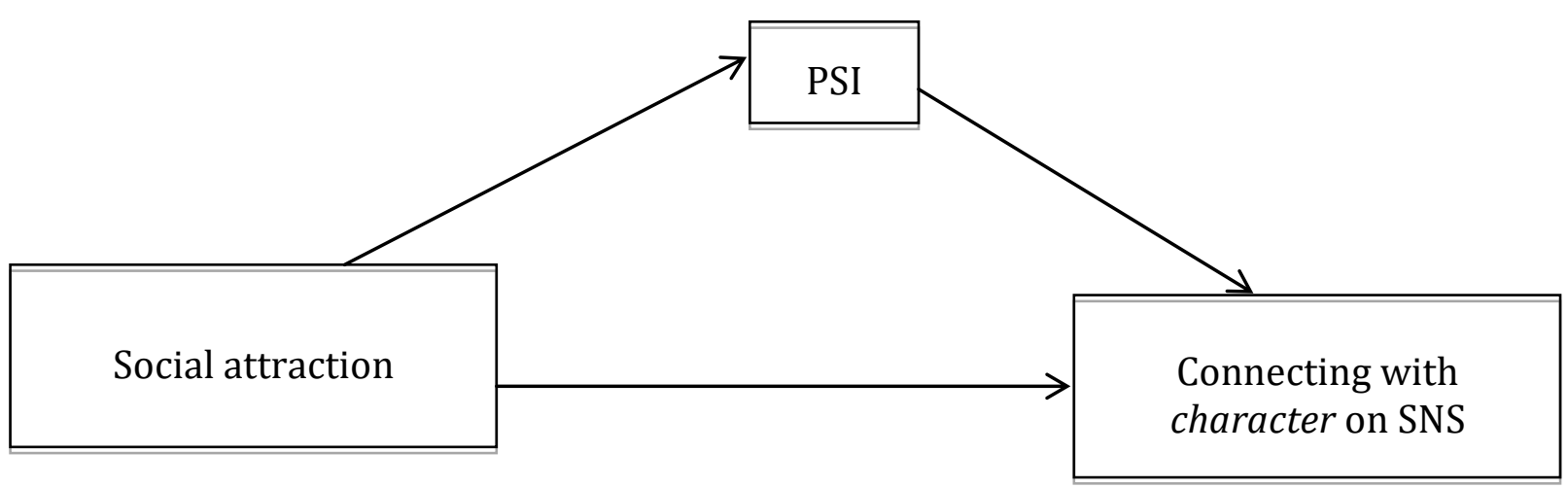

Figure 1. PSI as a mediator of social attraction on connecting with character on SNS 


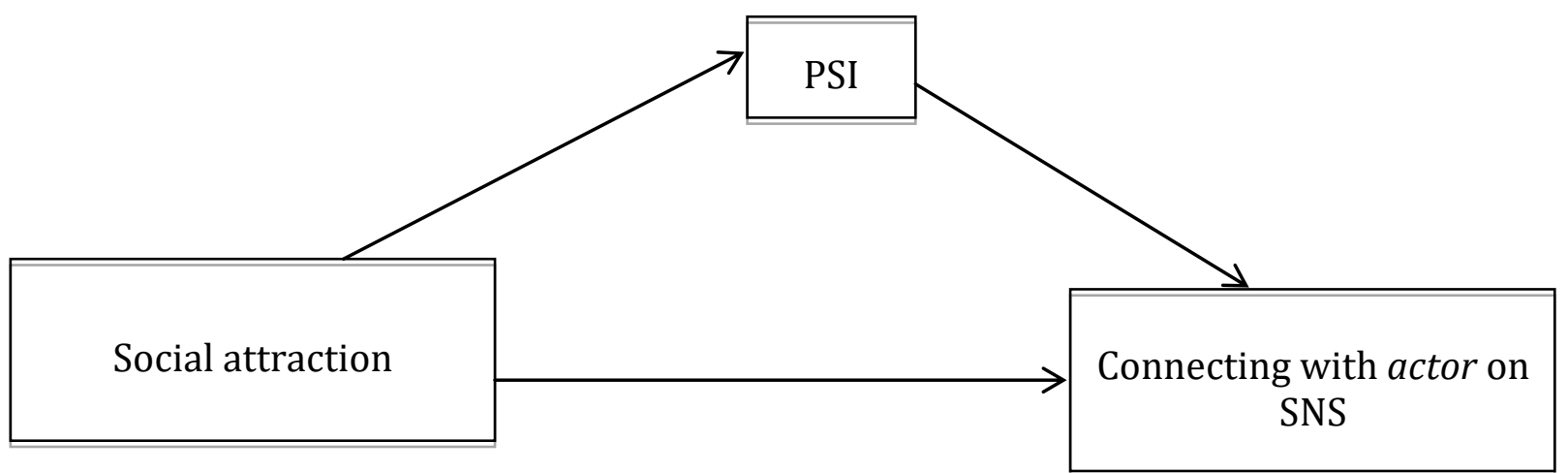

Figure 2. PSI as a mediator of social attraction on connecting withactor on SNS

\section{Method}

\section{Participants and Procedure}

Participants were 168 students recruited from various communication courses at a Midwestern university in exchange for course credit. The average age of the participants was 20years ( $S D$ $=2.8)$, and $80 \%(n=107)$ were females. Given, the sample was biased in terms of gender, it is added as a control variable in all the analyses to alleviate any effects gender may have on the results. The study was approved by the institution's review board for human subjects research. The data was collected in a large hall-type setting during a regular class period, after seeking permission from the instructor. Participants were asked to switch off their cell phones and laptops while watching a 30-minute segment from the show Mad Men (Season 1, episode 1). The reason participants were exposed to a clip before watching the show was because we wanted to understand levels of engagement, i.e., transportation in and identification with the show. Hence, instead of implementing a survey only design, this current approach was used where participants were first exposed to the narrative following which they responded to a survey. They were instructed not to talk to anyone during the process. The video focused on Don Draper, the main protagonist from the show Mad Men, who is shown contemplating creative idea for a campaign for a cigarette company as the client.

\section{Measures}

Exposure to the show Mad Men. One item asked each participant to indicate their frequency of viewing the show Mad Men on a 7-point scale (1-never watched to 7-watched all the time; $\mathrm{M}=1.45, \mathrm{SD}=1.12)$ and if they had previously watched the episode used in the study $(80 \%$ of the participants had not viewed the episode prior to the research). 
Identification. Identification with the protagonist Don Draper was measured using twelve items on a 7-point (1-strongly disagree to 7-strongly agree) scale (Cohen, 2001; $\alpha=.90 ; M=$ 4.16, $S D=1.07)$. A sample item included, "I think I have a good understanding of Don". Transportation. Engagement with the narrative was measured with the 11-item scale developed by Green and Brock (2000). Response options were 1 (strongly disagree) to 7 (strongly agree) $(\alpha=.76 ; M=4.34, S D=.87)$. A sample item is, "I wanted to learn how the story ended".

Parasocialineraction (PSI). A 10-item, 1 (strongly disagree) to 7 (strongly agree) scale developed by Rubin and Perse (1987) was used to measure PSI with the character Don Draper $(\alpha=.88 ; M=4.07, S D=1.15)$. A sample item is, "Don makes me feel comfortable, as if I am with a friend".

Social attraction. How attracted participants were to the protagonist Don Draper was measured with five items adapted from McCroskey\& McClain (1974) using a 1 (strongly disagree) to 7 (strongly agree) scale $(\alpha=.79 ; M=4.07, S D=1.19)$. A sample item is, "I think Don could be a friend of mine".

Source evaluation. A nine-item semantic differential scale (Lee \& Jang, 2013) was used to measure evaluation of the character Don Draper. On a 7-point scale, the participants were asked to evaluate the character using the following adjectives:dishonest-honest; unpleasantpleasant, selfish-unselfish, unlikable-likable, unattractive-attractive, unfriendly-friendly, uninformedinformed, and incompetent-competent $(\alpha=.84 ; M=5.08, S D=.97)$.

Enjoyment. To measure participants' enjoyment, on a 1 (strongly disagree) to 7 (strongly agree) scale, they were asked to rate how enjoyable, entertaining, interesting, and likeable they found the video to be $(\alpha=.92 ; M=6, S D=.98)$.

SNS Usage. We measured SNS usage, primarily with respect to Facebook and Twitter usage, with the 11-item scale developed by McKinney, Kelly \& Duran (2012) using a 1 (never) to 5 (many times a day) scale $(\alpha=.81 ; M=3.86, S D=1.01)$. A sample item is, "How frequently do you use Twitter, overall?"

Intentions. Intentions to follow was measured by asking participants to indicate, using a 7point (Strongly Disagree to Strongly Agree) scale, how likely they were to follow the show Mad Men, character Don Draper, and actor Jon Hamm on Twitter and Facebook. Participant's reported intentions for each platform (i.e., Facebook and Twitter) for the show, character, and the actor were combined to obtain a measure of likelihood to follow the show $(r=.65, p<.01$; $M=2.4, S D=1.67)$, the character $(r=.69, p<.01 ; M=2.3, S D=1.62)$, and the actor $r=.72 ; M$ 
$=2.2, S D=1.71)$ on social media platforms.Pearson's correlations, instead of cronbach's alpha, were used as reliability indicators because only two items were combined (Einsinga, TeGrotenhuis, \& Pelzer, 2013). The participants who reported that they had already connected with the show, character or/and actor $(n=12)$ were removed from the analyses.

In addition to the above, one item each asked participants to identify the number of Facebook friends $(M=727, \mathrm{SD}=376$, Median $=765$, Min = 20, $\mathrm{Max}=2000)$ and Twitter followersthey had $(M=209, S D=161$, Median = 188, Min =0, Max=980). Extreme values of having Twitter followers over 10,000 were removed, resulting in a minimal loss of data.

\section{Results}

For all the reported analysis the following variables were used as controls: frequency of viewing the show Mad Men, previous exposure to the episode used in the research, demographic variables (age and gender), social media usage habits, and enjoyment experienced during the viewing. Coefficients reported are unstandardized.

The first hypothesis, which proposed that transportation in the narrative would predict connecting with the show on various SNSpost-viewing, was supported. Regression analysisconducted with the abovementioned control variables revealed that the model significantly predicted connecting with the show on SNS, $F(7,118)=4.06, p<.001 ., R^{2}=.19$. Transportation in the narrative was a significant predictor of liking or following the show on SNS $b=.41(.19), t(118)=2.2, p=.03$. SNS usage behavior $b=.36(.14), t(118)=2.6, p=.01$; and enjoyment experienced during the viewing $b=.35(.17), t(118)=2, p=.05$ were other significant predictor of connecting with the show on SNS platforms.

$\mathrm{H} 2$ and RQ1 were tested together. In a linear regression model identification PSI, and control variables were added simultaneously. The regression model with the outcome variable, following the character on SNS was significant, $F(8,117)=4.40, p<.001 ., R^{2}=.18$. PSI was predictive of connecting with the character $b=.38(.15), t(117)=2.53, p=.01$. Identification did not have a significant effect on the dependent variable, $b=.16(.16), t(117)=.95 p=.34$. SNS usage was only other significant predictor in the model, $b=.26(.13), t(117)=2, p=.05$. 
The regression model with the outcome variable, following the actor on SNS was also significant, $F(8,116)=4.9, p<.001 ., R^{2}=.2$. PSI was predictive of connecting with the actor, $b=.32(.16), t(116)=2.06, p=.04$. Identification did not have a significant effect on the dependent variable, $b=.03(.17), t(116)=.15 p=.88$. SNS usage was only other significant predictor in the model, $b=.46(.14), t(116)=3.37, p<.01$.

The next set of hypotheses proposed PSI as a mediator of the effect of social attraction on following the character ( $3 a$ ) and the actor ( $3 b$ ) on SNS. This was tested using PROCESS macro (Hayes, 2013), model 4. In the mediation model, social attraction significantly predicted PSI, $b=.5, t(118)=6.86, p<.0001$ and PSIsignificantly predicted connecting with the character on SNS, $b=.61, t(117)=4.32, p<.0001$. The direct effect of social attraction on connecting with the character on SNS was significant, $b=-.26, t(117)=-1.98, p=.05$. The indirect effect after including the mediator was also significant thus indicating partial mediation, $b=.31$, $95 \% \mathrm{CI}$ $(.16, .53)$. Thus, H3a was supported.

$\mathrm{H} 3 \mathrm{~b}$ followed a similar pattern of findings as H3a. In the mediation model, social attraction significantly predicted PSI, $b=.5, t(117)=6.88, p<.0001$ and PSI significantly predicted connecting with the character on SNS, $b=.5, t(116)=3.39, p<.01$. The direct effect of social attraction on connecting with the character on SNS was significant, $b=-.28, t(116)=-2.07$, $p<.05$. The indirect effect after including the mediator was also significant thus indicating partial mediation, $b=.25,95 \% \mathrm{CI}(.09, .48)$. Thus, $\mathrm{H} 3 \mathrm{~b}$ was also supported.

\section{Discussion}

In this study, factors that influence people's decision to connect with a show and the celebrity in that show on social networking platforms were explored. As hypothesized, narrative involvement was a strong predictor of maintaining a need for connection with the drama, the character, and the actor even after the viewing experience ended. Specifically, transportation experienced while viewing was predictive of intention to connect with the show after the viewing experience had ended. Parasocial interaction during viewing, and not identification, was predictive of connecting with both the character and the actor via SNS post viewing. PSI also mediated the effect of source attraction on post-viewing involvement with the character and the actor via connecting with them on SNS. Overall, the findings of the study suggest that involvement in a narrative is a strong predictor of connecting with the narrative world once the 
viewing experience has ended. In other words, participants seem to maintain this need for connection, which is gratified via participation in SNS. These findings are provocative at many levels given recent research finding that suggests a direct correlation between Twitter activity and television ratings (Nielsen, 2013). Though, no causal inferences could be drawn, this study found that increased activity on Twitter was directly associated with an increase in total rating points (TRP) for the show and, conversely, the show that had higher ratings evoked a higher level of engagement on Twitter. Yet another study found that interaction on SM during program viewing enhanced engagement amongst message recipients (Pynta et al., 2014). The current study adds to this research by suggesting involvement with the narrative and its characters as one of the processes driving this effect.

The findings of the study have several implications. First, these findings suggest that in order to maintain an engaged audience, producers and the networks on which these programs are aired need to make sure that social media channels involving the show and the protagonists are created in a manner that keeps the audience engaged (Pynta et al., 2012). Further, such online engagement with the narrative world may reinforce the desire for a continuous subsequent interaction with the narrative given media selection is influenced by attitudinal outcomes shaped by exposure to media in the first place (Slater, 2007, 2014). This may be one of the explanations behind the relationship foundbetween Twitter activity and TV ratings (Nielsen, 2013; Pynta et al., 2014). Future research should examine this possibility.

Furthermore, perhaps message recipients, in the first place, seek out specific media due to an affinity towards an actor that they may have been exposed to in other places as suggested in the reinforcing spirals model that emphasizes that " the effects of media exposure are likely to reinforce the tendencies, preferences, and values that predict media choice in the first place" (Slater, 2007, p. 298-299). Indeed, a recent research found that social attraction to the actress Anne Hathawaypredicted transportation into the narrative and parasocial interaction with the character in the storyline even when the character was portrayed as stigmatized (Chung \& Moyer-Guse, 2012). Therefore, maintenance of online communities for fans of actors and characters could help in driving ratings and traffic, a possibility that needs more investigation.

The findings of this study are also important from a perspective of entertainment education that argues that deliberate and purposive embedding of educational messages in the form of 
entertainment might “increase audience member's knowledge about an educational issue, create favorable attitudes, shift social norms, and change overt behavior" (Singhal\& Rogers, 2002 p. 5). These findings suggest that narrative processes don't end with the narrative but continue even after the viewing experience is terminated. Previous research reported a similar finding that identification with the characters in the show motivated message recipients to engage in discussions regarding sexual behavior two weeks later (Moyer-Guse, Chung, \& Jain, 2011). Because social media provides a venue that may carry over (and reinforce) message effects, entertainment education scholars should broaden their attention to include online platforms in intervention efforts. Future research should examine the influence of continued engagement with the narrative world on SNS platforms on message recipient's attitudes and behaviors. If a protagonist with whom one identifies with, and engages in PSI with, was to espouse a particular message on SNS platform, would one more likely to adopt the espoused position during the post hoc SNS engagement if the viewer is also connected to them via SNS? Preliminary evidence from this study suggests a continuation of narrative engagement experience that is gratified via SNS after the viewing experience has ended. Previous research suggests that inclusion of an explicit persuasive appeal as an epilogue from the actor who played the protagonist in the narrative influenced drunk-driving attitudes among message recipients (Moyer-Guse, Jain, \& Chung, 2012).Future research should examine the influence of connecting with a narrative character on SNS on message recipient's longterm attitudes. Perhaps observational learning from the narrative and continued motivation provided via engagement in related online networks may drive people to adopt positive attitudes and expectancies-a possibility that remains to be explored (Bandura, 1986, 2002).

Another implication of this study is that continued engagement post viewing could lead to attitudinal conformity. Cameron and Geidner's (2014) work suggests that dual viewing, that is engaging simultaneously with content on traditional medium such as TV and SNS such as Twitter, leads to opinion conformity in line with the majority opinion expressed on Twitter. The authors in this study did not measure engagement variables but the mere effect of seeing a majority positive or negative opinion on Twitter influenced viewer's perceptions. Given, narrative engagement is, to some extent, an investment of self in the message and its characters, another possibility for future research may examine the subsequent effects on opinion conformity should be reified for those message recipients who are highly invested and engaged 
in the story and its characters. This again alludes to the potential of using these characters and shows for entertainment-education purposes.

At a theoretical level, this study raises the questions regarding the concept of parasocial breakup (Cohen, 2003, 2004; Lather \& Moyer-Guse, 2011) that suggests the negative affect experienced when a show ends or a favorite character in a program dies or is taken off the air. Given the pervasiveness of social media and the presence of television shows and characters on these platforms, perhaps viewers don't feel as much distress when their favorite show is taken off the air, as suggested in previous research, because they know that continued interaction is a possibility. Maybe when the show or the character stops adding content to their social media platform or exhibits lack of engagement that is when the real breakup occurs? And even after that, the engagement provided via online community may act as a buffer against the distress experienced as a result of the breakup. All theses possibilities remain to be tested.

This research, though promising, was not without its limitations. Though utmost care was exercised during the study, errors in survey research due to subject-related issues such as fatigue and self-report cannot be ruled out. Further, behavioral intention to connect with the show and celebrities was measured. Though intention is a good indicator of behavior, assessment of actual behavior would have provided more confidence in findings. However, because it is not feasible to see if participants connected with the show without being given access to their social networks (e.g. by being participant's friend) a conscious decision to use intention measure was used as a proxy so as to not violate participants' privacy. Another limitation of the study is that the data is collected from a convenient sample of students and uses one viewing of a particular show. Therefore, future research should repeat the study with a more diverse sample and multipleshows. However, given just one show and one viewing had significant impact on outcome variables of interest, this limitation also demonstrates the strength of the study; if one time exposure could have such an impact, repetitive long term relationship with the show is only going to magnify the effects.

These results clearly indicate that narrative involvement process does not end with the viewing experience and one motivation behind connecting with the programs and celebrities after the show has ended could be related to the involvement during viewing. It is important to note that the majority of the participant sample in this study were not regular viewers of the show Mad 
Men. Despite that, however, participants who reported to be involved in the narrative or with the character, expressed intentions to connect with them via different SNS post viewing. This suggests the importance of narrative engagement and its long-term influence. These findings are especially striking given most media organizations are adopting Web 2.0 and striving to gain audience attention by enhancing online engagement. Recent research has pointed to the power of narratives and of SNS in influencing attitudes and behaviors. This study adds to the literature by bringing these two distinct concepts together and urges future research to examine how this framework could be utilized for prosocial messaging. In so doing, this study bridges previousresearch on narrative processing of entertainment shows, uses and gratification, and social media engagement. 


\section{References}

Albiniak, P. (2012a). Syndies get social; shows connect with viewers via Pinterest, Tumblr, GetGlue, UStream, others. Broadcasting and Cable.

Albiniak, P. (2012b). No stopping till everyone "likes" Katie; Disney-ABC uses waealth of social media to promote Couric's new talker. Broadcasting and Cable.

Bandura, A. (1986). Social foundation of thought and action: A social cognitive theory. Englewood Cliffs, NJ: Prentice-Hall.

Bandura, A. (2009). Social cognitive theory of mass communication. In J. Bryant \& M. B. Oliver (Eds.), Media effects: Advances in theory and research (2nd ed., pp. 94-124). Mahwah, NJ: Lawrence Erlbaum.

Baron, R. M., \& Kenny, D. A. (1986).The moderator-mediator variable distinction in social psychological research - conceptual, strategic, and statistical considerations.Journal of Personality and Social Psychology, 51(6), 1173-1182.

Busselle, R., \& Bilandzic, H. (2008).Fictionality and perceived realism in experiencing stories: A model of narrative comprehension and engagement. Communication Theory, 18(2), 255-280.

Cameron, J., \& Geidner, N. (2014). Something old, something new, something borrowed from something blue: Experiments on dual viewing TV and Twitter. Journal of Broadcasting and Electronic Media.

Chung, A. H., \& Moyer-Guse, E. (2012).Predicting narrative involvement from social attraction to an actor. Retrieved from http://citation.allacademic.com/meta/p_mla_apa_research_citation/5/5/5/8/8/p555880 _index.html?phpsessid=c4q4abkbdqb30qhrvap6ikr0p5

Ciacu, N., \& Tănase, T. (2012).Television in the social media era. Communication \& Marketing / Revista De Comunicare Si Marketing, 3(4), 95-107.

Cohen, J. (2001). Defining identification: A theoretical look at the identification of audiences with media characters. Mass Communication \& Society, 4(3), 245-264.

Cohen, J. (2003). Parasocial breakups: measuring individual differences in responses to the dissolution of parasocial relationships. Mass Communication \& Society, 6(2), 191202.

Cohen, J. (2004). Parasocial break-up from favorite television characters: the role of attachment styles and relationship intensity. Journal of Social and Personal Relationships, 21(2), 187-202. doi:10.1177/0265407504041374 
Cohen, J. (2006). Audience identification with media characters. Psychology of Entertainment, 183-197.

Cohen, J. (2014). Mediated relationships and social life: Current research in fandom, parasocial relationships, and identification. In M. B. Oliver \& A.A. Raney (Eds.), Media and social life (pp. 142-156).New York, NY: Routledge.

Eisinga, R., TeGrotenhuis, M., \& Pelzer, B. (2013). The reliability of a two-item scale: Pearson, Cronbach, or Spearman-Brown? International journal of public health, 58(4), 637-642.

Giles, D. C. (2002).Parasocial interaction: A review of the literature and a model for future research. Media Psychology, 4(3), 279-305.

Green, M. C., \& Brock, T. C. (2000).The role of transportation in the persuasiveness of public narratives. Journal of Personality and Social Psychology, 79(5), 701.

Green, M. C., \& Brock, T. C. (2002).In the mind's eye: Transportation-imagery model of narrative persuasion.Narrative Impact: Social and Cognitive Foundations, 315-341.

Green, M. C., \& Clark, J. L. (2013). Transportation into narrative worlds: implications for entertainment media influences on tobacco use. Addiction, 108(3), 477-484.

Greer, C. F., \& Ferguson, D. A. (2011a). Using Twitter for promotion and branding: a content analysis of local television twitter sites. Journal of Broadcasting \& Electronic Media, 55(2), 198-214. doi:10.1080/08838151.2011.570824

Greer, C. F., \& Ferguson, D. A. (2011b). Following local television news personalities on Twitter: A uses and gratifications approach to social networking. Electronic News, 5(3), 145-157. doi:10.1177/1931243111420405

Hayes, A. F. (2013). Introduction to mediation, moderation, and conditional process analysis: A regression-based approach. New York: The Guilford Press.

Habibi, M. R., Laroche, M., \& Richard, M. (2014). Brand communities based in social media: How unique are they? Evidence from two exemplary brand communities. International Journal of Information Management, 34(2), 123-132.

Harrison, K. (1997). Does interpersonal attraction to thin media personalities promote eating disorders? Journal of Broadcasting and Electronic Media, 41, 478-500.

Horton, D., \& Wohl, R. R. (1956).Mass communication and para-social interaction.Psychiatry, 19, 215-229.

Katz, E., Blumler, J., \& Gurevitc, M. (1973). Uses and gratifications research.Public Opinion Quarterly, 37(4), 508-523. 
Jain, P., \& Slater, M. (2012, May) Deliberative versus non-deliberative evaluations of international-medical-graduate physicians after viewing a medical drama. Paper presented at the Annual Meeting of International Communication Association, Phoenix, AZ.

Larsson, A. O. (2013). Tweeting the viewer - Use of Twitter in a talk show context. Journal of Broadcasting and Electronic Media, 57(2), 135-152.

Lather, J., \& Moyer-Guse, E. (2011). How Do We React When Our Favorite Characters Are Taken Away? An Examination of a Temporary Parasocial Breakup. Mass Communication And Society, 14(2), 196-215.

Lin, J. \& Peña, J. (2011). Are you following me? A content analysis of TV networks' brand communication on Twitter.Journal of Interactive Advertising, 12(1), 17-29.

Lee, E.-J., \& Jang, J. (2013). Not so imaginary interpersonal contact with public figures on social network sites: how affiliative tendency moderates its effects. Communication Research, 40(1), 27-51. doi:10.1177/0093650211431579

McCroskey, J. S., \& McClain, T. A. (1974). The measurement of interpersonal attraction. Speech Monographs, 41(261-266).

McKinney, B. C., Kelly, L., \& Duran, R. L. (2012). Narcissism or openness?: College students' use of Facebook and Twitter. Communication Research Reports, 29(2), 108118. doi: 10.1080/08824096.2012.666919

Moyer-Guse, E. (2008). Toward a theory of entertainment persuasion: explaining the persuasive effects of entertainment-education messages. Communication Theory, $18(3), 407-425$.

Moyer-Gusé, E., Chung, A., \& Jain, P. (2011).Identification with characters and discussion of taboo topics after exposure to an entertainment narrative about sexual health. Journal of Communication,61, 387-406.

Moyer-Guse, E., Jain, P., Chung, A. (2012).Reinforcement or reactance?Examining the effect of an explicit persuasive appeal following an entertainment-education narrative. Journal of Communication, 62(6), 1010-1027.

New Nielsen Research Indicates Two-Way Causal Influence Between Twitter Activity and TV Viewership. (n.d.). Retrieved March 31, 2014, from http://www.nielsen.com/content/corporate/us/en/press-room/2013/newnielsenresearch-indicates-two-way-causal-influence-between-.html 
Pai, P., \& Arnott, D. C. (2013). User adoption of social networking sites: Eliciting uses and gratifications through a means \& end approach. Computers in Human Behavior, 29(3), 1039-1053.

Papacharissi, Z., \& Rubin, A. M. (2000). Predictors of internet use. Journal of Broadcasting \& Electronic Media, 44(2), 175.

Social Media Update 2013 | Pew Research Center's Internet \& American Life Project.(n.d.). Retrieved March 31, 2014, from http://www.pewinternet.org/2013/12/30/socialmediaupdate-2013/

Pynta, P., Seixas, S. a. S., Nield, G. E., Hier, J., Millward, E., \& Silberstein, R. B. (2014). The power of social television: can social media build viewer engagement? A new approach to brain imaging of viewer immersion.Journal of Advertising Research, 54(1), 71-80.doi:10.2501/JAR-54-1-071-080

Van Reijmersdal, E. A., Jansz, J., Peters, O., \& van Noort, G. (2013). Why girls go pink: Game character identification and game-players' motivations. Computers in Human Behavior, 29(6), 2640-2649. PersCom

Rubin, A. M., \& Perse, E. M. (1987).Audience activity and soap opera involvement a uses and effects investigation.Human Communication Research, 14, 246-268. doi: 10.1111/j.1468-2958.1987.tb00129.x

Rubin, A. M. (2009). Uses-and-gratification perspective on media effects. In Media effects: Advances in theory and research. Edited by Jennings Bryant and Mary Beth Oliver, 165-184. New York: Routledge.

Rubin, R. B., \& McHugh, M. P. (1987).Development of parasocial interaction relationships. Journal of Broadcasting and Electronic Media, 31(3), 279-292.

Ruggiero, T. E. (2000). Uses and Gratifications Theory in the 21st Century. Mass Communication \& Society, 3(1), 3-37.

Singhal, A. \& Rogers, E. M. (2002).A theoretical agenda for entertainmenteducation. Communication Theory, 12(2), 117-135.

Slater, M. D. (2002). Entertainment education and the persuasive impact of narratives. Narrative Impact: Social and Cognitive Foundations, 157-181.

Slater, M. D., \&Rouner, D. (2002). Entertainment-education and elaboration likelihood: understanding the processing of narrative persuasion. Communication Theory, 12(2), 173-191. 
Slater, M. D. (2007). Reinforcing spirals: the mutual influence of media selectivity and media effects and their impact on individual behavior and social identity. Communication Theory, 17(3), 281-303. doi:10.1111/j.1468-2885.2007.00296.x

Slater, M. D. (2014). Reinforcing spirals model: Conceptualizing the relationship between media content exposure and the development and maintenance of attitudes. Media Psychology,

Tal-Or, N., \& Cohen, J. (2010). Understanding audience involvement: Conceptualizing and manipulating identification and transportation. Poetics, 38(4), 402-418. doi: 10.1016/j.poetic.2010.05.004

Toubia, O., \& Stephens, O. (2013). Intrinsic versus image related motivations in social media: Why do people contribute content to Twitter? Marketing Science.

Tully, M., \& Ekdale, B. (2014). The team online: entertainment-education, social media, and cocreated messages. Television \& New Media, 15(2), 139-156. doi: $10.1177 / 1527476412455952$

Wohn, D. Y., \& Eun-Kyung, N. (2011). Tweeting about TV: Sharing television viewing experiences via social media message streams.First Monday, 16(3), 1. 